\title{
The Research of Integration Design Method of Prefab Aluminum Architecture
}

\author{
Ling Dong ${ }^{1, \text { a }}$, Yu Wang ${ }^{2, b}$ \\ ${ }^{1}$ Nanjing Tech University, Department of Architecture, Puzhu South Road No.30, Nanjing city, \\ Jiangsu province, China \\ ${ }^{2}$ Southeast University, Department of Architecture, Sipailou NO.2, Nanjing city, Jiangsu province, \\ China \\ ad007larc@163.com, bwangyu840309@126.com,
}

Keywords: Prefabrication, Aluminium architecture, Integration design.

Abstract. As a kind of excellent light precast construction materials, aluminum alloy has the advantage of light weight, high accuracy, corrosion resistance, recyclable, etc. This thesis mainly does research on the integration method based on BIM of prefab aluminum architecture, including assembly, performance and flow of constriction. This research will help to develop the strategy of standardization, modularization and sustainability of native prefab architecture system.

\section{Introduction}

More than one century has passed since construction transferred from total site work to factory prefabricating . Building industry has obtained great benefits from the development of prefab building, including the less onsite time of construction, the save of labor and cost, the improve of quality.

The integration method is the core of Prefab Building. In the beginning of 20th century, the precast technology obtained significantly development with the Mass Production Theory pursued by Fordism, as well as the urgent demand of house; although, With a lack of focus on integration, early attempts at factory production collapsed without firm ground up foundations in place ${ }^{[1]}$. After the 1960s, the development of integration method based on information technology which began to change other industries such as automobile, shipbuilding has become the important foundation of the innovation of modern prefab architecture. The new integration idea combined with BIM technology plays an huge role in promoting the precast technique forward after 21 th century.

In 2008, the exhibition" Home Delivery: Fabricating the Modern Dwelling " held in the Museum of Modern Art, where the integration technology of modern prefab architecture was adequately displayed, including the Aluminum Prefab Architecture. As a kind of environmentally friendly material conforming to [4R] principle, aluminum has a application in the building, what's more, the application has gradually extended from components to integrated structure system.

Nowadays the research of Prefab Aluminum Architecture has not been fully carried out, though the industrial aluminum profile has been widely used in construction industry in China. Taking integration theory as its studying subject, and aluminum prefab architecture as its perspective of research, and BIM technology as its method, this paper, carries out the research of prefab architecture system meeting with the needs of local constriction industry, and will help to promote the development of native light prefab system.

\section{Methods}

\section{Integrated Assembly}

The integration of assembling is the core technique of the prefab architecture. In order to realize quick construction on site with the components produced in factory, the size of component as well as the connection type both need to be design in integrated ways. The basic two main principles of integrated method of assemble are standardization - with a limited number of sizes selected for their combinatorial value; and modular coordination - providing a numerical measure for determining those 
standard sizes. what's more, another principle -tolerance, which exist to accommodate the normal manufacturing and installation inaccuracies that occur in construction has become more and more important.

In the end of 20th century, the prefab technique began to upgrade with the development of Cybernetic Factory ${ }^{[2]}$. The strategy of module assemble represent the principle of "more is less" : add the flow of production, but reduce the cost of labor and time. The process of construction is distributed to different department at one time through the division of module, each module is designed and manufactured by independent group but connected by the BIM. As a result, the CE ( Concurrent Engineering )decreases the connection of on-site job, improve the quality of final assembly. The assembly processes for all these joints ensure quality control through built-in registers that render it impossible for parts to be misaligned. They simply will not fit together at all if they are not aligned properly. ${ }^{[3]}$

\section{Integrated Performance}

In addition, the integration method is also widely applied to the performance design of component in order to improve the living environment and promote the development of building sustainability. The members of traditional architecture usually just undertook one function, but for nowadays, the prefab components consisting of different "layers" has already had the ability to undertake multiply function. For example, the layers that integrated on a wall produced in factory have several function including load bearing, thermal insulation, ventilation and so on.

From the beginning of the 20th century, the proportion of mechanical and electrical equipment has rapidly grown up from $5 \%$ to $30 \%$. As a result, the integrated elements also extended from construction field to the combination field of both construction and mechanical, electrical elements. Performance integration put forward higher requirements for the research of interdisciplinary. The technique concerning with BIM provides the important condition for the design and analysis of integration performance design in the early stage. In this way, different characters such as architects, structure engineer, equipment engineer, process engineer, material scientists can work cooperatively at the same time to solve the specific performance requirement of different building.

\section{Integrated Process}

With the development of integration technology, the process of production changes as well. As opposed to design-bid-build (DBB), design-build(DB) projects "reduce the overall project duration." ${ }^{4]}$ Procurement methods such as DB allow for early decision making regarding prefabrication systems that can lead to improved coordination and construct ability, and finally reduced construction time. In addition, Konchar and Sanvido, in a 1998 study, found benefits of DB in terms of cost and quality, an added benefit with prefabrication. ${ }^{[5]}$

The new DB process makes the seamless combination between the department of design and production come true through the help of information tool. One of the key elements in integrated processes is the selection and participation of all project personnel as early in the project as possible. As an effective approach to realize integrated assembly and performance, the integrated process not only improves the efficiency of design, the ability to control the cost, but also the potential of architecture technology innovation.

\section{A Case Study-Low Energy Consumption Prefab Aluminum Architecture}

The prefab aluminum architecture is a new kind of light building product with the advantage of multifunction, high quality and sustainability, which can be used for temporary or urgent construction requirements. What's more, the research of prefab aluminum architecture has been carried out throughout the world, including China.

\section{Research process based on "open-loop"}

In order to motivate the creativity of production research, the DB model was established at the beginning. The design team is also the manufacture team and construction team. The "loop" means that the team consisting of different characters is operated by the unified organization, at the same time, the 
process of research also keep the openness to the extensive production industry to maintain the continuity and sustainability of research(Fig.1).

The information management platform based on BIM is established to realize the quick communication

between different departments with the sharing, exchanging and feedback of the same model. While the accurate model with construction information can be split into several modules, then the different department can put forward the research work at one time. In the end, the BOM(the bill of material ) output by BIM is transmitted to different enterprise to finish final manufacture(fig.2).

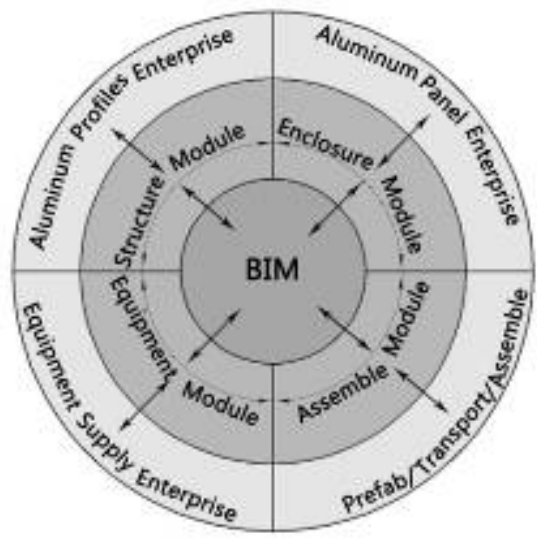

Fig.1Open-loop

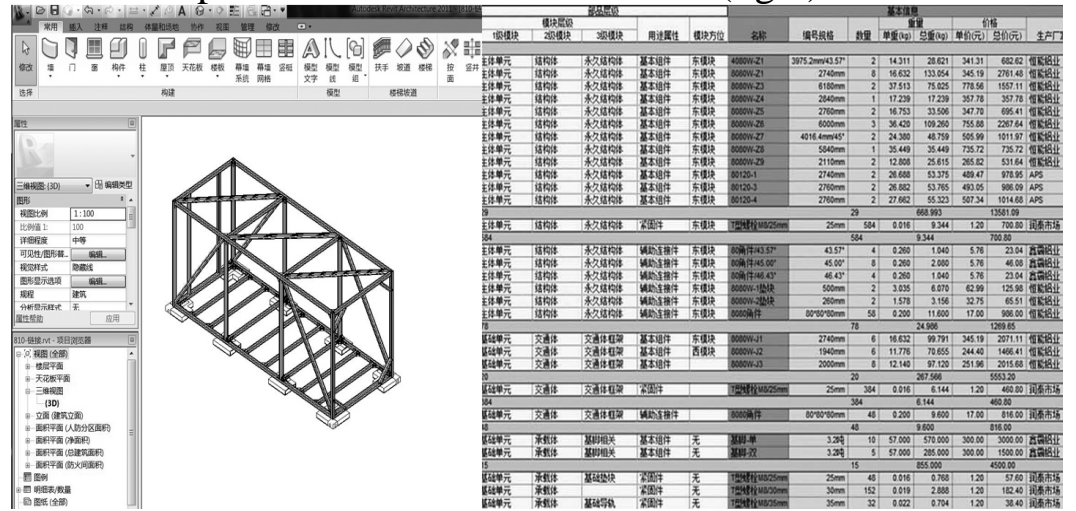

Fig.2BOM output by BIM

\section{Module design based on BIM}

Nowadays module design has been become the necessary means to realize high quality and efficiency of prefabrication. According to the object, the module can be divided into two types: Design Module and Assembly Module.

The first kind is an abstract division of design process beyond the real material, which including construction module(foundation, structure, components, etc), performance module(Mechanic, thermal, aesthetic), equipment module(HVAC, water supply and drainage, communication, etc ), tolerance module, transportation module, etc(Fig.3).

The second kind is an specific division of construction method based on integrated design and manufacture of factory. It is also can be considered as the extension and deepening of design module. In this case, construction module is divided into three main part: foundation platform module, box unit module and the solar equipment module(Fig4). The three module separately undertakes the function of loading bearing, defining function space and energy supply. The BIM technique ensures the paralleled design and product of different module carrying out at same time, as well as the high speed and quality of final construction on site.

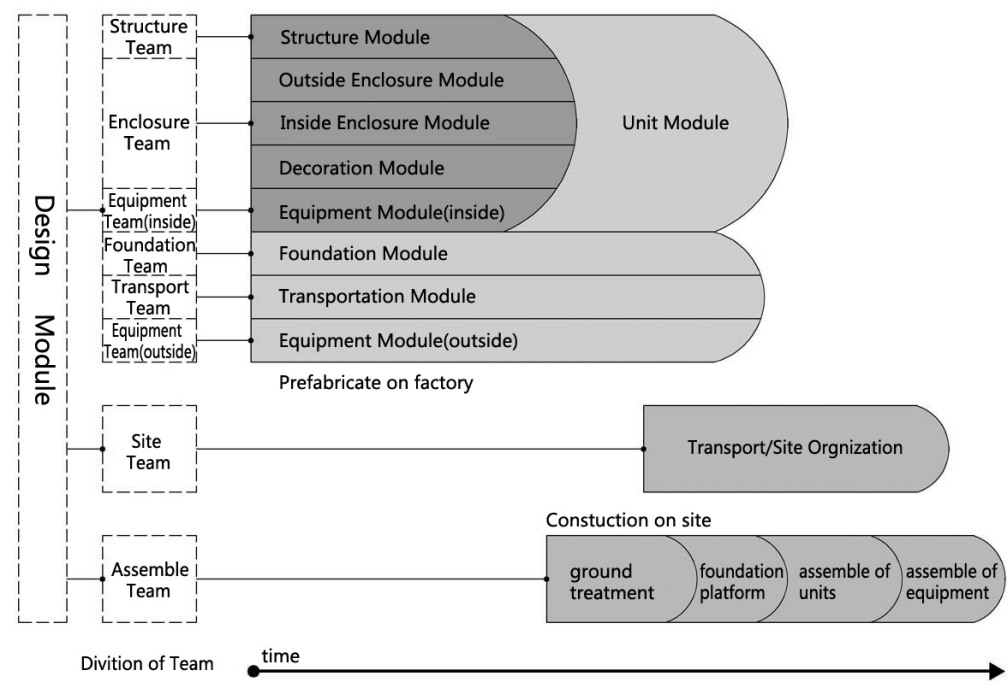

Fig.3Design Module 


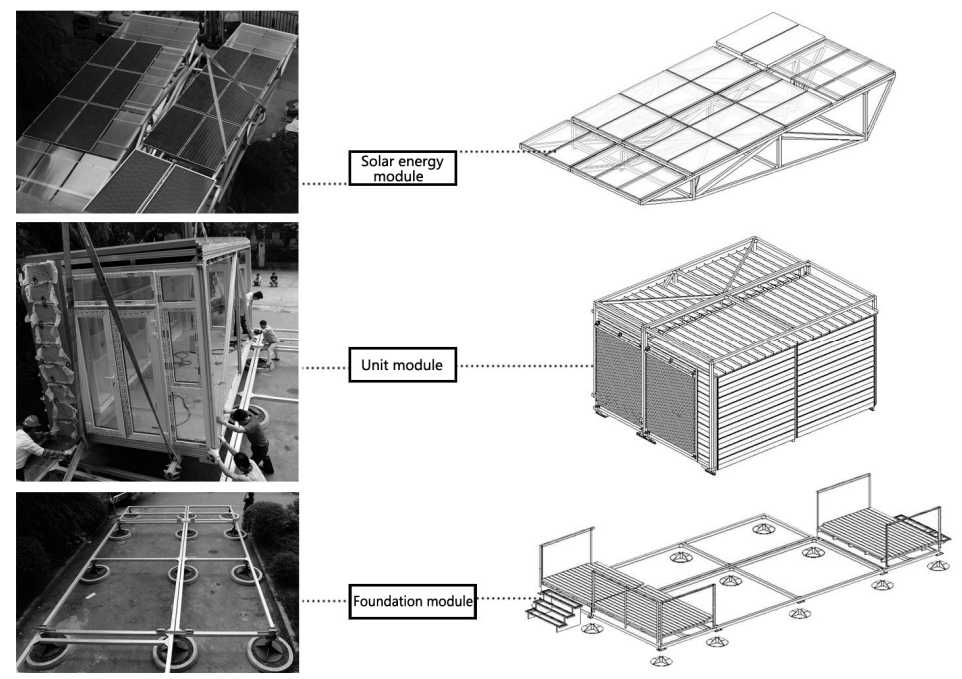

Fig.4Assembly Module

\section{Integration customized components}

Although the industrial aluminum profile can meet with the need of unit structure requirement, but there is no existing technique for the other products such as foundation, enclosure component, joint of module, etc to refer. As a result, several integrated components need to be specially customized according to specific requirement.

One of the components is integrated panel which is also the important performance element of light construction system. A kind of double heat insulation construction panel is designed in consideration of the cold bridge that may occur. The detail of construction is eventually confirmed by the result simulated and calculated by Energy plus tool: a compound layer consisting of $4 \mathrm{~mm}$ aluminum panel, $60 \mathrm{~mm}$ polyurethane, $25 \mathrm{~mm}$ wood panel $+70 \mathrm{mmrockwool}+25 \mathrm{~mm}$ wood panel $+0.2 \mathrm{~mm}$ aluminum foil (from outside to inside).(Fig.5)
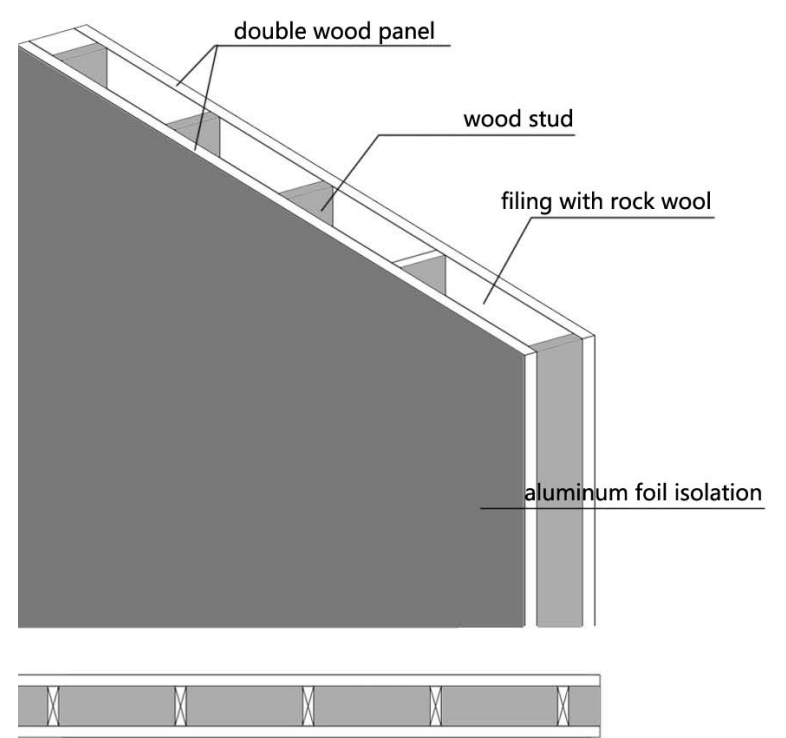

the integrated hollow wall

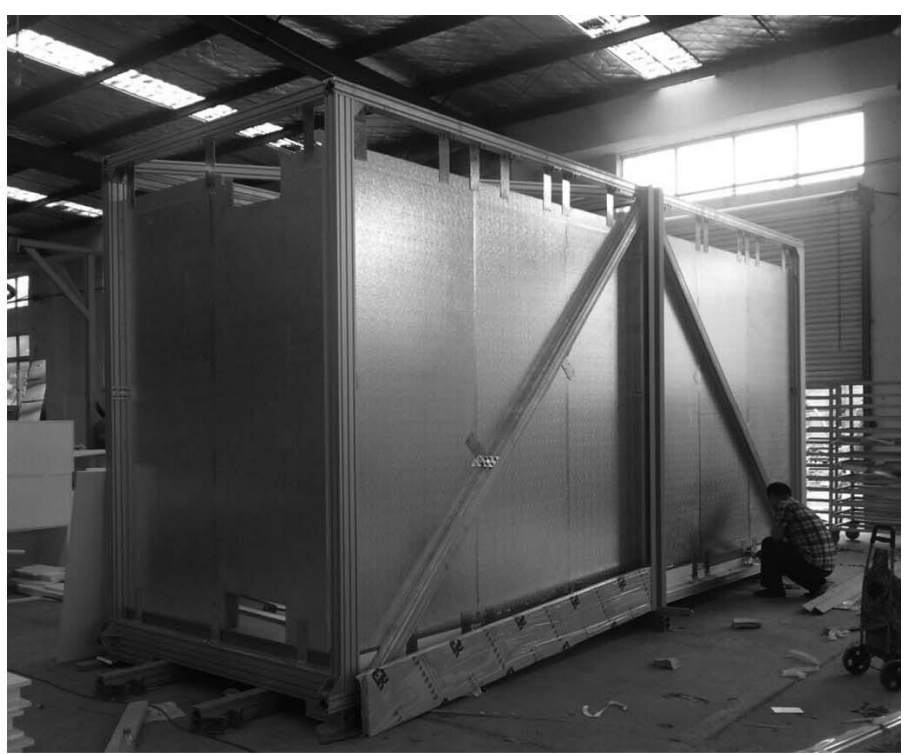

the inside thermal isolation wall cut off the "cold bridge"

Fig.5integrated performance component design

The foundation component not only need the stable support ability, but also need a portable form and some kind of flexibility so as to satisfy the requirement of quick construction and various terrain. For this purpose, the team designed a kind of independent foundation component for which the height can be adjust. The new component is mainly made up with screw jack, which has high bearing capacity, easy operability and extensive adaptability(Fig.6). 


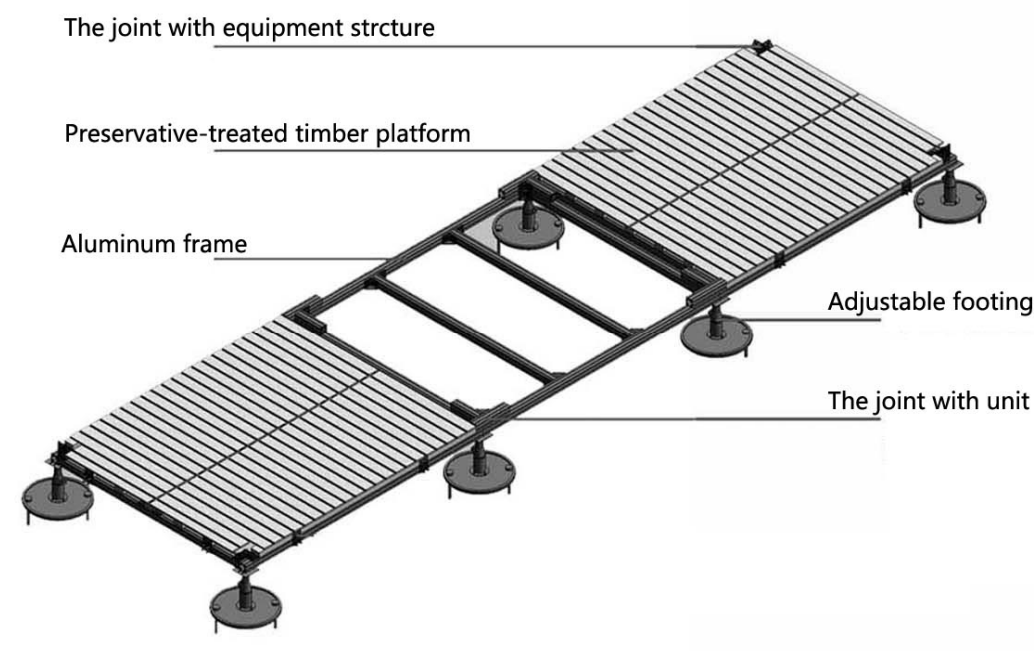

Foundation module

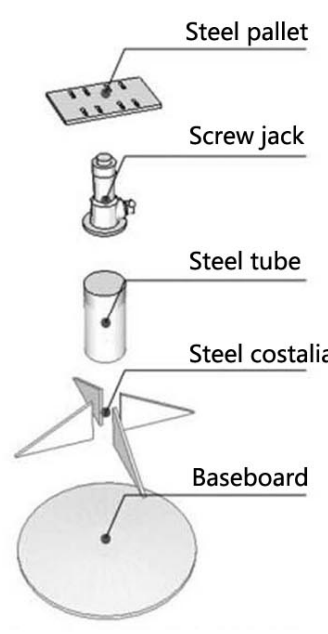

Adjustable footing

Fig.6integrated foundation component design

The construction seam is necessary for the tolerance of construction, at the same time, the assurance of high quality of fabrication needs the special integration design of units connection, which can be used for locating unit, moving unit to the right place and finishing the work of fill the seam automatically. With this construction integrated of fixing, locating, sliding and elastic, the efficiency of final construction is highly improved.(fig7)

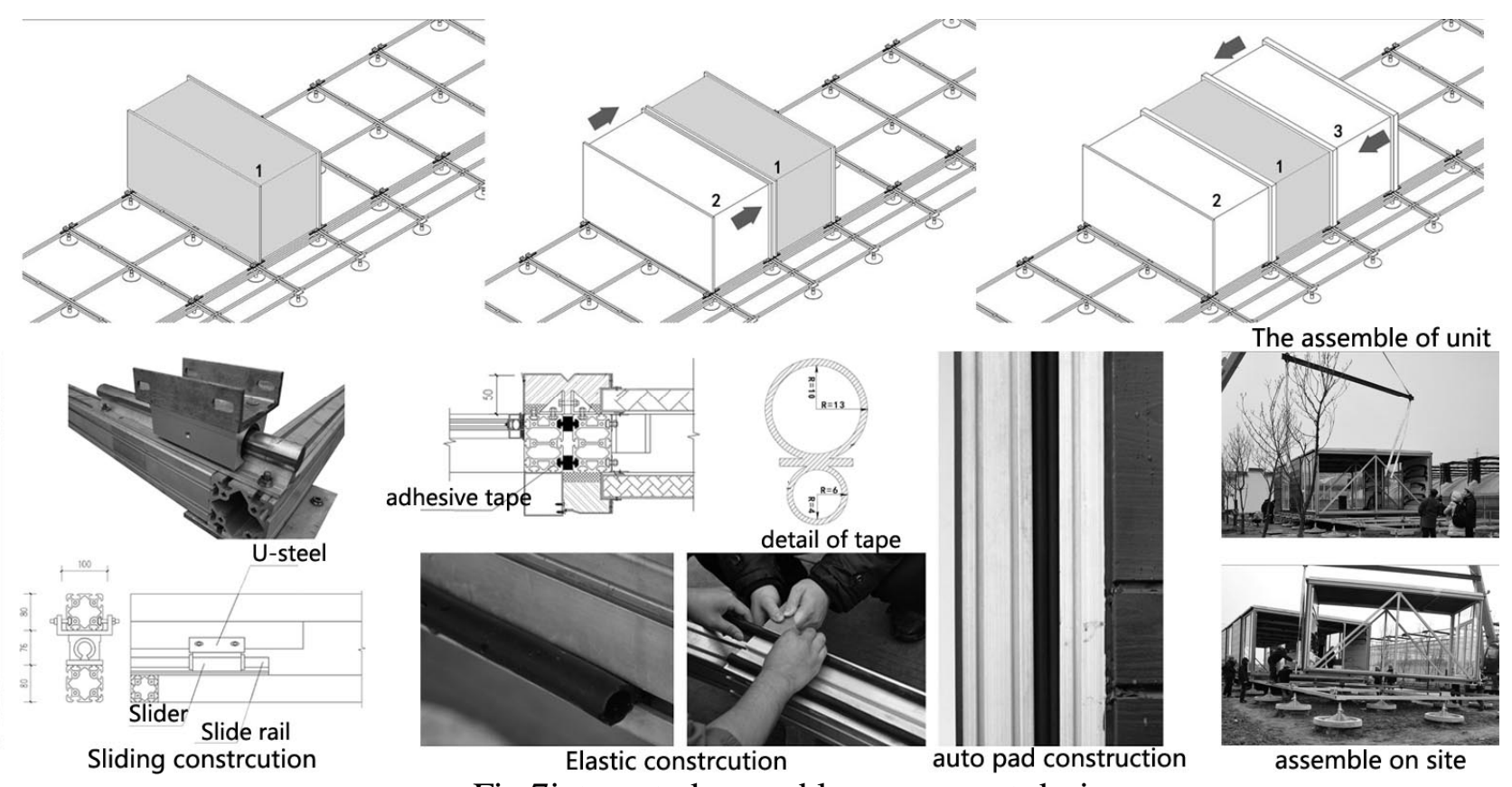

Fig.7integrated assembly component design

\section{Conclusions}

From the case study mentioned above, we find that the construction process is becoming more and more simple, efficiency and accurate. There is little question that the prospect of a fully integrated, computerized design, manufacturing and construction process summons up a challenging vision, in which, at its ultimate, on-site robots complete the enforcement of human intelligence and craft skills described earlier.

This new transition of prefab architecture development is just like what is stated by Chris Abel: "This shift can in turn be interpreted, at a higher level, as part of a new, more balanced Modernist 
philosophy, which allows the architect to pay due respect to what is particular to a place and regional environment, as well as making the most of the technological culture all industrialized countries now share." [6]

\section{Acknowledgements}

This work was financially supported by the National Nature Science Foundation of China (51278109), Oriented Towards Body and Topography: Research on the Taconic Theory and Localized Strategy under the Half-Industrialization .

\section{References}

[1] RYAN E. SMITH, Prefab architecture : a guide to modular design and construction, John Wiley \& Sons, Inc. New Jersey( 2010), in press: p8

[2] Chris Abel: Architecture and Identity-Responses to cultural and technological change, Architectural Press, NY( 2000), in press: p25

[3] Stephen Kieran, James Timberlake: Refabricating Architecture, McGraw-Hill, NY(2004), in press: p112

[4] C. Eastman, P. Teicholz, R. Sacks, and K. Liston, BIM Handbook: A Guide to Building Information Modeling for Owners, Managers, Designers, Engineers and Contractors , Hoboken: John Wiley and Sons, Inc. New Jersey (2008), in press: p382.

[5] M. Konchar and V. Sanvido, "Comparison of U.S.Project Delivery Systems." Journal of Construction Engineering and Management ,American Society of Civil Engineers, 1998 : 124(6): 435-444.

[6] Chris Abel: Architecture and Identity-Responses to cultural and technological change, Architectural Press , NY( 2000), in press: p61 